\title{
Giant mediastinal teratoma-bull in a china shop: Management strategies
}

\author{
Lakhvinder S. Vohra, MS, ${ }^{a}$ Rajnish Talwar, MS, ${ }^{a}$ Mala Mathur, MS, ${ }^{a}$ Chadalavada Venkata R. Mohan, MD, ${ }^{c}$ \\ Naveen Chawla, MD, and Ramanathan Saranga Bharathi, MBBS, ${ }^{b}$ Pune, Maharashtra, India
}

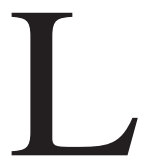

arge thoracic tumors behave in a similar manner to an enraged bull in a china shop when they grow, despite treatment with neoadjuvant chemotherapy (NACT). Management strategies should be tailored to meet the challenges posed by the rapidity of growth and enormity of size of these giants. We report a case of a patient with large and heavy malignant mediastinal teratoma, in which the intensity of compressive features caused by spiraling growth, despite NACT, necessitated urgent surgery using a combination of incisions that were individually inadequate and perilous for safe tumor removal.

\section{Clinical Summary}

A mediastinal mass was radiologically detected in a 24 -year-old man who presented with chest pain and a dry cough of 2 months' duration. Serial x-ray films showed the rapid increase in mass size, mediastinal shift to the right with onset of dyspnea, and prominent veins in the superior vena cava (SVC) territory. Computed tomography (CT) revealed a large, heterogenous, anterior mediastinal mass abutting the pericardium and left hilar vessels, displacing the heart to the extreme right and collapsing the left lung (Figure 1). CT-guided biopsy suggested nonseminomatous germ cell tumors. Tumor markers were elevated (alpha-fetoprotein, $95 \mathrm{ng} / \mathrm{mL}$; betahuman chorionic gonadotropin, $25 \mathrm{mIU} / \mathrm{mL}$; lactate dehydrogenase, $723 \mathrm{IU} / \mathrm{L}$ ). Platinum-based NACT was administered to the patient. However, SVC syndrome and dyspnea rapidly worsened. In view of the spiraling deterioration, urgent surgery under general anesthesia, with unilateral lung ventilation and bilateral thoracic paravertebral catheterization, was performed. A median sternotomy provided inadequate exposure for extracapsular dissection and tumor delivery; thus, a lateral sternal split with anterior thoracotomy was performed at the level of the third intercostal space. The left lung expanded within minutes of tumor removal. The patient had a remarkable postoperative recovery and was removed from the ventilator within 6 hours of surgery. The tumor weighed

From the Malignant Diseases Treatment Centre, Command Hospital (Southern Command) a ; Department of Surgery, Armed Forces Medical College $^{\text {b; }}$ and Department of Anesthesiology and Critical Care, Armed Forces Medical College, ${ }^{\mathrm{c}}$ Pune, Maharashtra, India.

Received for publication Nov 25, 2006; accepted for publication Dec 12, 2006.

Address for reprints: Maj. Ramanathan Saranga Bharathi, Assistant Professor, Department of Surgery, Armed Forces Medical College, Pune, Maharashtra, India 411040 (E-mail: sarangabharathi@rediffmail.com/ rsarangabharathi@yahoo.co.in).

J Thorac Cardiovasc Surg 2007;133:1382-3

$0022-5223 / \$ 32.00$

Copyright @ 2007 by The American Association for Thoracic Surgery doi:10.1016/j.jtcvs.2006.12.053
$5 \mathrm{~kg}$ and measured $34 \times 24 \times 14 \mathrm{~cm}$ (Figure 2). Histopathology confirmed the diagnosis of malignant teratoma. The tumor grade could not be assessed because of necrosis and NACT.

The patient has now completed second-line chemotherapy.

\section{Discussion}

Teratomas account for $1 \%$ to $5 \%$ of mediastinal (anterior) tumors, which vary widely in maturity. ${ }^{1-3}$ With a peak incidence in the second and third decades of life, teratomas vary in presentation from incidental detection on radiographs to life-threatening respiratory distress. ${ }^{2,3}$ When present, symptoms result from the mechanical effect on the surrounding structures, causing chest pain, cough, dyspnea, and recurrent pneumonitis. ${ }^{3}$ Erosion into the tracheobronchial tree produces a cough emitting sebaceous material and hair, which is considered pathognomonic. ${ }^{3}$

Teratomas escape detection to become large (largest reported was $\sim 2.5 \mathrm{~kg}$ ) because of expansion at the cost of compliant thoracic tissues and organs with abundant functional reserve. ${ }^{2}$ However, accelerated growth within the rigid thoracic cage results in respiratory and cardiovascular compromise and SVC syndrome. ${ }^{1-3}$ Local invasion or rupture into the pleural and pericardial cavity produces cardiac tamponade, pleural effusion, and hemothorax, resulting in surgical urgency. ${ }^{4,5}$ In our case, intensification of compressive features by spiraling tumor growth necessitated urgent surgery to relieve the mass effect.

CT is the imaging of choice in the detection and planning management of these tumors. ${ }^{3,6}$ Mediastinal teratomas manifest as

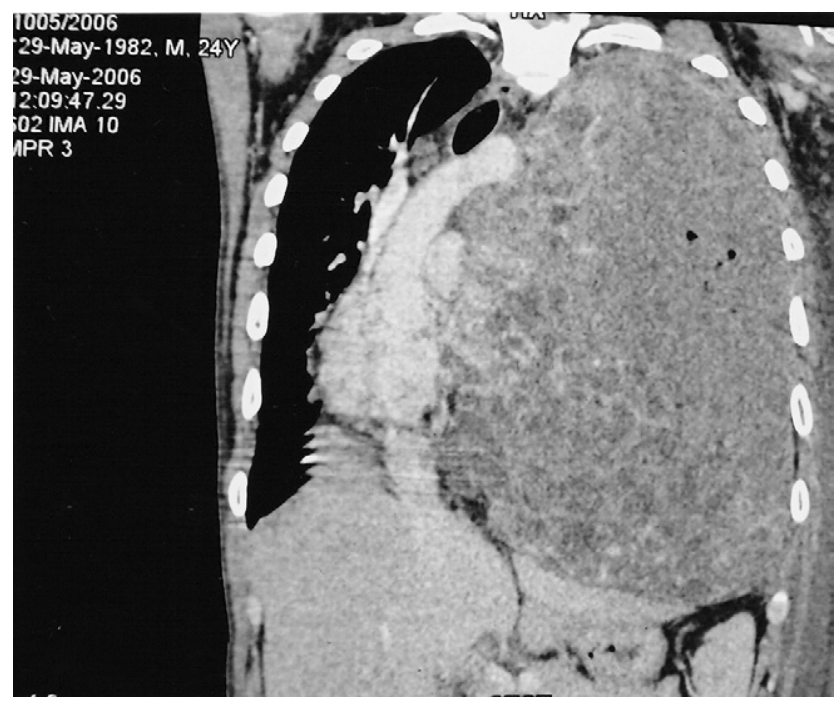

Figure 1. CT scan of thorax showing the extent of mass and mediastinal shift. CT, computed tomographic. 


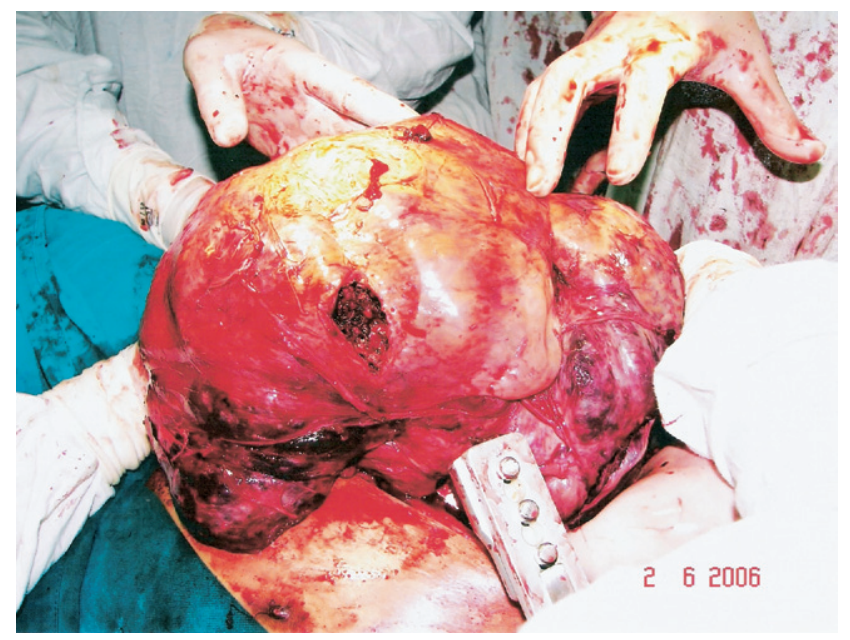

Figure 2. Tumor delivery in progress through the thoracic wound showing its size and adequacy of incision.

a heterogeneous anterior mediastinal mass containing a combination of soft tissue, fluid, fat, and calcium attenuation. ${ }^{6}$ Cystic lesions without fat or calcium are seen in $15 \%$ of cases. ${ }^{6}$ Fat-fluid levels are considered specific for mature teratomas. ${ }^{6}$

Tumor markers, such as beta-human chorionic gonadotropin, lactate dehydrogenase, and alpha-fetoprotein, are frequently elevated. Tissue diagnosis is often elusive and is achieved on tumor excision.

Surgical removal constitutes adequate treatment for mature teratomas, but immature teratomas are best managed by platinumbased NACT followed by elective surgical removal. ${ }^{1-3}$ However, worsening compressive features, as in our case, might force tumor excision to take precedence.

Smaller mediastinal tumors ( $\sim 560 \mathrm{~g})$ have been successfully excised with thoracoscopy, ${ }^{7}$ but median sternotomy provides the best exposure for larger anterior mediastinal masses. ${ }^{8}$ However, large tumors, closely applied and adherent to vital structures and distorting local anatomy, require more exposure than that provided by median sternotomy to prevent catastrophic collateral damage. A clamshell incision provides bilateral exposure, but it may not provide the necessary vertical dimension for manipulation. We found a lateral sternal split with anterior thoracotomy at the level of the left third intercostal space, in addition to median sternotomy, necessary for safe extracapsular tumor dissection and delivery. Complications of surgery include bleeding, pleural effusion, pyothorax, and phrenic nerve damage, the majority of which can be prevented by adequate access and exposure.

In residual tumors and in patients in whom extracapsular tumor resection is not feasible because of adhesions and invasion, the addition of radiation therapy may prove useful. ${ }^{3}$ The prognosis in such cases and in malignant teratomas, overall, is poor. ${ }^{3}$

In-dwelling paravertebral and epidural catheters provide painless postoperative recovery and early restoration of physiologic respiratory function by early weaning from the ventilator. We preferred a paravertebral catheter because of the risk of epidural bleeding in SVC syndrome.

The rapid growth of a large mediastinal teratoma, despite NACT, is rare and may precipitate surgical urgency because of the escalation of compressive features. A median sternotomy may provide inadequate exposure for safe excision of large tumors. The addition of a lateral sternal split and anterior thoracotomy may provide the requisite exposure.

\section{References}

1. Takeda S, Miyoshi S, Ohta M, Minami M, Masaoka A, Matsuda H. Primary germ cell tumors in the mediastinum: a 50-year experience at a single Japanese institution. Cancer. 2003;97:367-76.

2. McLeod NP, Vallely MP, Mathur MN. Massive immature mediastinal teratoma extending into the left pleural cavity. Heart Lung Circ. 2005; 14:45-7.

3. Lau CL, Davis RD Jr. The mediastinum. In: Townsend CM, Beauchamp RD, Evers BM, Mattox KL, editors. Sabiston Textbook of Surgery. The Biological Basis of Modern Surgical Practice. Philadelphia, PA: Saunders; 2004;1735-62.

4. Yang WM, Chen ML, Lin TS. Traumatic hemothorax resulting from rupture of mediastinal teratoma: a case report. Int Surg. 2005;90:241-4.

5. Lee M, Lee Y, Ikusima H, Chin S, Lee M, Sakurai M. Resection of mediastinal teratoma in a patient with cardiac tamponade due to pericardial perforation. Nippon Kyobu Geka Gakkai Zasshi. 1991;39:1771-6.

6. Moeller KH, Rosado-de-Christenson ML, Templeton PA. Mediastinal mature teratoma: imaging features. AJR Am J Roentgenol. 1997;169: 985-90.

7. Takeo S, Fukuyama S. Video-assisted thoracoscopic resection of a giant anterior mediastinal tumor (lipoma) using an original sternum-lifting technique. Jpn J Thorac Cardiovasc Surg. 2005;53:565-8.

8. Koga H, Yamataka A, Kobayashi H, Miyamoto H, Lane GJ, Miyano T. Median sternotomy provides excellent exposure for excising anterior mediastinal tumors in children. Pediatr Surg Int. 2005;21:864-7. 